Cite as: Kupeli, N., Chilcot, J., Schmidt, U.H., Campbell, I.C., \& Troop, N.A. (2012). A confirmatory factor analysis and validation of the Forms of Self-criticism/Selfreassurance Scale. British Journal of Clinical Psychology. In press.

\title{
A confirmatory factor analysis and validation of the Forms of
}

\section{Self-criticism/Self-reassurance Scale}

Nuriye Kupeli, Joseph Chilcot, Ulrike H Schmidt, lain C. Campbell, and Nicholas A. Troop

Correspondence to:

Nuriye Kupeli, Department of Psychology, University of Hertfordshire, Hatfield, Herts AL10 9AB; email n.kupeli4@herts.ac.uk

Keywords: Self-criticism, self-reassurance, self-compassion, confirmatory factor analysis 


\begin{abstract}
Objective: Several studies have used the Forms of Self-Criticism/Reassurance Scale (FSCRS; Gilbert, Clarke, Hempel, Miles \& Irons, 2004) when exploring the role of emotion regulation in psychopathology. However, psychometric evaluation of the FSCRS is limited. The present study sought to confirm the factor structure of the FSCRS based on theoretical and empirical grounds in a large sample of the general population.

Method: The FSCRS was completed by a large sample of men and women $(N=1570)$ as part of an online survey. The data were randomly split in order to perform both independent exploratory (EFA) and confirmatory factor analyses (CFA). One-, two- and three-factor solutions were examined.

Results: A three-factor model of reassured-self (RS) and the two types of self-criticism, inadequate-self (IS) and hated-self (HS), proved to be the best fitting measurement model in this sample $\left(\chi^{2}=800.3, \mathrm{df}=148, p<.001 ; \mathrm{CFI}=.966, \mathrm{TLI}=.961, \mathrm{RMSEA}=.074\right)$. Although very similar to the original questionnaire, there were some differences in terms of the items that were retained. Validity was confirmed with the shortened FSCRS showing the same associations with mood and sex as the original version of the FSCRS. Conclusion: A three-factor model (reassured-self, inadequate-self and hated-self) provided the best fitting structure and confirmed the separation of different types of self-criticism. Future research should explore the degree to which these separable aspects of self-criticism are theoretically and clinically meaningful and to identify the role of self-reassurance in ameliorating their effects.
\end{abstract}




\section{Introduction}

Self-critical thoughts have proved to be an important factor in adaptation and have been explored from a range of perspectives including coping (e.g. Coyne et al., 1981; Folkman \& Lazarus, 1985; Tobin et al., 1989; Vitaliano et al., 1985), strategies of thought control (e.g. self-punishment: Wells \& Davies, 1994; Reynolds \& Wells, 1998), restoring assumptions about a just world (Janoff-Bulman, 1992), emotion regulating self-talk (Brinthaupt, Hein, Kramer, 2009) and personality risks for depression (e.g. Blatt \& Homann, 1992). According to Blatt \& Homann (1992), self-criticism in the face of failure to achieve goals concerns the "constant and harsh self-scrutiny and evaluation and a chronic fear of being disapproved of or criticized, and of losing the approval and acceptance of significant others" (p.528). Self-criticism predicts psychopathology (e.g. Dunkley, Sanislow, Grilo \& McGlashan, 2009) and interferes with progress towards important goals (Powers, Koestner, Lacaille, Kwan \& Zuroff, 2009).

Recently, Gilbert, Clarke, Hempel, Miles and Irons (2004) elaborated on earlier single-factor measures of self-criticism by developing their Forms of SelfCriticism/Reassurance Scale (FSCRS). Arguing from an evolutionary perspective, Gilbert proposes that competencies for co-ordinating roles with others are used in selfevaluations. In the case of self-criticism, "competencies and behaviours for the hostile dominating of others ... and those for acting as a threatened subordinate ... can interact at the subjective (self-to-self) level" (Gilbert et al., 2004, p.33). In contrast, the ability to 
reassure oneself at times of difficulty may reflect a learned ability to be compassionate directed internally (Gilbert, 2005).

Gilbert et al. (2004) developed the FSCRS to measure self-criticism and selfreassurance in a sample of 246 female students. The construct of self-criticism was divided into two types of self-criticism, inadequate-self (e.g. "I can't accept failures and setbacks without feeling inadequate") and hated-self (e.g. "I call myself names"), while self-reassurance (e.g. "I can still feel lovable and acceptable") emerged as a distinct factor.

Studies using the FSCRS show that reacting with self-criticism predicts outcomes such as depression and anxiety (e.g. Gilbert, Clarke, Hempel, Miles, \& Irons, 2004; Gilbert, Baldwin, Irons, Baccus, \& Palmer, 2006), self-harm (Gilbert, McEwan, Irons, Bhundia, Christie, Broomhead \& Rockliff, 2010) and disordered eating (Kupeli, Chilcot, Platts \& Troop, 2012). In contrast, greater self-reassurance is related to better psychological health (Gilbert et al., 2004, 2006). Self-reassurance is proposed to develop as a consequence of internalising parental soothing (Gilbert, 2006) and empirical evidence suggests this is the case with self-reassurance being related to security of attachments (Irons, Gilbert, Baldwin, Baccus \& Palmer, 2006) and early memories of warmth and safeness (Richter, Gilbert \& McEwan, 2009).

Although the FSCRS is being increasingly used to measure self-criticism and selfreassurance, its factor structure has been evaluated only once (Gilbert et al., 2004) when describing the measure's original development. The use of this scale in a range of clinical and non-clinical male and female participants belies the fact that its factor 
structure was developed in a sample of 246 female students. Clearly further psychometric evaluation is warranted and the present paper explores the factor structure further.

In determining the potential number of factors of the FSCRS there are several lines of evidence to suggest one, two and three factor solutions. Firstly, of course, is that the principal components analysis performed by Gilbert et al. (2004) found a threefactor solution, two self-criticism factors (inadequate-self [IS] and hated-self [RS]) and one self-reassurance (reassured-self [RS]) factor. Evidence that IS and HS are genuinely separable types of self-criticism includes the fact they show different patterns of associations - e.g. hated-self is uniquely predictive of self-harm, depression and anxiety (Gilbert et al., 2004, 2010) while inadequate-self is uniquely predictive of disordered eating (Kupeli, Chilcot, Platts \& Troop, 2012) and is associated with motives for selfcorrection (Gilbert et al., 2004). Furthermore, one study found that, while responses to inadequate-self covered the full distribution range, those for hated-self showed a floor effect (Longe, Maratos, Gilbert, Evans, Volker, Rockliff \& Rippon, 2010). If the scales were simply part of the same factor they would be expected to have the same distribution of responses. In spite of this, studies using the FSCRS have generally found inter-correlations between the two self-criticism factors of between .68 and .72 (e.g. Gilbert et al., 2004; Irons et al., 2006; Richter et al., 2009) with one study even reporting a correlation of .80 (Gilbert et al., 2010). Such high inter-correlations indicate a risk of multi-collinearity in regression analysis (Howell, 2002). Accordingly, many studies have combined IS and HS subscales into a single factor (e.g. Gilbert et al., 2006; Rockliff et al., 
2011). This could be taken as tacit acknowledgement that the FSCRS contains only two factors, self-criticism (IS + HS) and self-reassurance (RS).

Yet other evidence suggests that self-criticism/reassurance may even represent opposite ends of a single factor. In developing the Self-Compassion Scale (Neff, 2003a), Neff (2003b) proposes there are three components of self-compassion: 1 ) kindness towards the self rather than critical self-judgement (similar to the constructs of selfreassurance and self-criticism, respectively), 2) common humanity in which it is accepted that failure and pain are part of the human experience (rather than a perceived isolation from this human experience), and 3) mindful awareness of negative emotional states in which these are faced and accepted rather than denied or exaggerated (as in over-identification of emotional states). Exploratory and confirmatory factor analyses suggest these components form a single factor with the constructs of self-kindness, common humanity and mindful awareness being positively loaded and critical self-judgment, isolation and over-identification (of emotional response) being negatively loaded. Higher levels of self-compassion (incorporating high levels of self-kindness and low levels of critical self-judgment) predict better psychological health (e.g. Neely, Schallert, Mohammed, Roberts \& Chen, 2009; Neff, 2003a, 2004; Neff, Kirkpatrick \& Rude, 2007a; Neff, Rude \& Kirkpatrick, 2007a; Neff \& Vonk, 2009).

Although self-compassion is clearly a broader construct than just self-criticism and self-reassurance, there is some similarity between items for the FSCRS selfreassurance and SCS self-kindness scales as well as between FSCRS self-criticism and SCS 
critical self-judgment scales. For example, for self-reassurance/self-kindness there are the items "I am gentle and supportive with myself" versus "I try to be loving towards myself" and "I am able to care and look after myself" versus "I give myself the caring and tenderness I need" for the FSCRS and SCS respectively. For self-criticism/critical selfjudgment there are the items "I can't accept failures and setbacks without feeling inadequate" versus "I'm disapproving and judgmental about my own flaws and inadequacies" and "I call myself names" versus "I can be a bit cold-hearted towards myself" for the FSCRS and SCS respectively.

Since in the SCS critical self-judgment and self-kindness scales form a single higher-order factor, the similarity with FSCRS scales of self-criticism and self-reassurance suggests these two may also form a single factor. However, a recent fMRI study showed that inducing self-critical and self-reassuring responses led to activation in different areas of the brain (Longe et al., 2010). Clearly, though related, and in spite of Neff's (2003a) measure of self-compassion combining similar constructs into a single higherorder factor, self-criticism and self-reassurance would seem to be distinct processes. Nevertheless, whether a 2- or a 3-factor solution is a better representation of these constructs is uncertain and, however unlikely, a single-factor model of the FSCRS is at least still feasible. Therefore, for the sake of parsimony, the present study will also consider a single, as well as a 2- and 3-factor solution.

In addition to confirming the factor structure of the FSCRS, the current paper will also validate the scale by exploring the relationship between the FSCRS and mood and by examining sex differences for each of the sub-scales of the FSCRS. The association 
between the FSCRS, specifically self-criticism, and mood has been established by many studies (Gilbert et al., 2004, 2006, 2010) and this relationship has also been found when studies have used other measures of self-criticism (Blatt, Quinlan, Chevron, McDonald \& Zuroff, 1982; Dunkley, Saislow, Grilo \& McGlashan, 2009). Secondly, previous research has demonstrated that women have lower levels of self-compassion (Neff, 2003a) and are more self-critical (Leadbeater, Kuperminc, Blatt \& Hertzog, 1999; Nolen-Hoeksema, Larson \& Grayson, 1999) than men. Therefore, it is hypothesized that females will show more feelings of inadequacy and hated self and less reassurance in comparison to males.

In summary, it is plausible that the FSCRS contains 1,2 or 3 factors. The aim of the present study is to confirm the factor structure of the FSCRS, explore the relationship between the individual scales and mood and examine sex differences using data gathered from a large predominantly community-based sample.

\section{Method}

Participants and procedure

Participants were recruited from two sources, 346 students from the University of Hertfordshire and 1224 participants recruited online through social networking sites and health and well-being forums. Participants from sample 1 were awarded with participation credit for taking part in a cross-sectional online study examining disordered eating (Troop, Choudhury, Wiseman, Hore, \& Ratcliff, 2012) whilst 
community-based participants from sample 2 were recruited as part of a longitudinal study investigating stress, mood, bodyweight and disordered eating. Participants from both samples completed the respective surveys online which were created using the Bristol Online Survey (BOS) facility. For the overall sample, mean age was 28.5 (s.d 10.6), and most participants were female, white, either employed or were students and either single or married/cohabiting (see Table 1).

Measures

The FSCRS is a 22-item measure, which requires participants to rate a selection of positive and negative statements on a 5-point Likert scale ranging from $0=$ not at all like me to 4 = extremely like me. This scale measures self-reassurance (reassured-self, RS) and two types of self-criticism, inadequate-self (IS) and hated-self (HS). Positive items reflect the ability to self-reassure and negative items indicate self-critical thoughts and feelings. Although in the original version higher scores on the three subscales indicated a stronger perception of that construct (i.e., greater sense of inadequacy, selfhate, self-reassurance), in order to carry out the analyses described below, positive (RS) items were reversed in order to be positively related to IS and HS items. For example, a response of ' 0 ' on the original scoring would indicate "Not at all like me" but when recoded, as a '4', it would indicate "Extremely like me". Thus, for the purpose of the present study, higher scores on positive (RS) items indicate less self-reassurance, thus higher scores across all three constructs represent a negative self-perception. 
Mood was assessed using the Short Depression-Happiness Scale (SDHS; Joseph, Linley, Harwood, Lewis and McCollam, 2004). The SDHS (Joseph et al., 2004) consists of 6 statements which requires participants to rate how they have felt over the last 7 days on a 4-point Likert scale ("Never" to "Often"). The SDHS (Joseph et al., 2004) is a bidirectional scale with lower scores indicating low mood and higher scores indicating greater happiness. Cronbach's alpha for the SDHS (Joseph et al., 2004) in the current study was $\alpha=.88$. The SDHS was administered only to sample 2 .

\section{Statistical analysis}

The data from both sources were combined before being randomly split. Exploratory Factor Analysis (EFA) was conducted using the first half of the randomly split dataset $(n=764)$ in Mplus version 6 (Muthén \& Muthén, 2010). Oblique Geomin rotation was employed since the extracted factors were expected to correlate. The number of factors extracted was based on the Kaiser criterion (eigenvalues $>1$ ) and the examination of a Scree plot. In addition, EFA using Mplus also allows model fit indices to be evaluated across several factor solutions. Items were removed from the EFA if their factor loadings were non-significant or if they loaded significantly but weakly (i.e., <.45) onto more than one factor.

The best fitting models identified from the EFA (after the removal of nonsignificant and double loadings) were subsequently selected for CFA using the second data file $(n=806)$ from which post-hoc modifications could be sought and evaluated. 
CFA is a measurement model which specifies the relationship of the observed measures to their hypothesised underlying constructs. CFA was conducted using Mplus version 6 (Muthén \& Muthén, 2010) with analyses computed using the Weighted LeastSquares with mean and variance adjustment (WLSMV). Mplus (Muthén \& Muthén, 2010) generates several fit indices to assess how well the proposed model fits the sample data. Firstly, the $\mathrm{Chi}^{2}$ statistic may be used as a measure of fit between the sample covariance and fitted covariance matrices (Byrne, 1998). A non-significant $\mathrm{Chi}^{2}$ is desired suggesting that the observed and reproduced covariance matrix do not differ significantly and thus demonstrate a good model fit. In addition to the $\mathrm{Chi}^{2}$ statistic several fit indices were evaluated including the Comparative Fit Index (CFI) and the Tucker Lewis Index (TLI). Values > .95 and above for these indices indicate a reasonable fit. The Root Mean Square Error of the Approximation (RMSEA) is another fit index, which takes into account the error of approximation in the population (Byrne, 1998). RMSEA values $<.05$ indicate a good model fit.

Similar to the original paper by Gilbert et al., (2004), further analyses were conducted to examine associations between the individual scales of the FSCRS and mood. Additional analyses were also conducted to examine sex differences for each of the subscales.

\section{Results}

\section{Sample characteristics}


The data set comprising of 1570 participants was randomly split in two data files from which EFA $(n=764)$ and CFA $(n=806)$ were conducted. Comparisons between the EFA and CFA samples with regards to demographic variables are shown in Table 1 . The two groups did not differ with respect to age, gender, ethnicity, marital and employment status. Furthermore individual items scores on the FSCRS did not differ between the groups (data not shown). These results suggest that the random split was successful thus allowing two independent samples to be analysed.

Table 1 here

\section{Exploratory Factor Analysis of FSCRS}

Before an EFA was conducted using Mplus, an EFA was conducted in SPSS to ensure the Kaiser criterion was met. EFAs comparing alternative factor models were then evaluated in Mplus. Three different factor solutions for FSCRS items were evaluated using EFA, which showed that a one-factor $\left(\chi^{2}=2307.9, \mathrm{df}=209, p<.001\right.$; $\mathrm{CFI}=.786, \mathrm{TLI}=.763, \mathrm{RMSEA}=.115)$ and two-factor solution $\left(\chi^{2}=1268.1, \mathrm{df}=188, p<.001\right.$; $\mathrm{CFI}=.890, \mathrm{TLI}=.864, \mathrm{RMSEA}=.087$ ) had poor fit to the data as evidenced by significant $\mathrm{Chi}^{2}$ tests and fit indices above threshold. A three-factor $\left(\chi^{2}=634.6, \mathrm{df}=168, p<.001\right.$; $\mathrm{CFI}=.952, \mathrm{TLI}=.934, \mathrm{RMSEA}=.06$ ) solution had acceptable fit to the data. Item factor loadings for the three-factor solution were examined which led to the removal of Item 4 ("I find it difficult to control my anger and frustration at myself ") due to a factor loading <.40. Items 18 ("I think I deserve my self-criticism") and 20 ("There is a part of me that wants to get rid of the bits I don't like") were also removed since their factor loadings 
were weak $(<.45)$ and were double loaded thus limiting their interpretation. Removal of these items did not influence the overall value of the measures of sampling adequacy (MSA=.948). The three-factor solution was re-tested after excluding items 4, 18 and 20 and it was found that model had superior fit to the data $\left(\chi^{2}=481.6, \mathrm{df}=117, p<.001\right.$; $\mathrm{CFI}=.958, \mathrm{TLI}=.938, \mathrm{RMSEA}=.06)$. Factor 1 contained 6 items and was labelled Inadequate-self $($ Eigen Value $=9.03$, variance explained $=47.52 \%)$. Factor 2 contained 5 items and was labelled Hated-self (Eigen Value $=1.67$, variance explained $=8.8 \%$ ). The final factor was labelled Reassured-self (Eigen Value $=1.28$, variance explained $=6.74 \%$ ). The rotated Geomin factor solution can be seen in table 2.

Table 2 here

Confirmatory Factor Analysis of the FSCRS

The three-factor model derived from the EFA was then evaluated in the second sample's data file using CFA. This model (model A) demonstrated a reasonable fit to the data as evidenced by the fit indices (see table 3). However, there were issues regarding item 22 ("I do not like being me"). In the original solution item 22 loaded onto the HS factor but examination of the modification indices suggested this item should also be predicted by the latent factor Reassured-self. When item 22 item is permitted to load onto both HS and RS scales (see model B, table 3), the fit is significantly better than when it is constrained to load only on the HS scale as shown by a Chi ${ }^{2}$ Difference test (DIFFTEST; $\Delta \chi^{2}=79.5, \mathrm{df}=1, p<.01$ ). The modified model (model $\mathrm{B}$ ) is shown in figure 1 
accompanied by standardized model coefficients. The three factors all showed logical interrelationships. Inadequate-self correlated highly with hated-self $(r=.82, p<.001)$ and reassured-self $(r=.66, p<.001)$. Hated-self and reassured-self also correlated highly $(r=$ $.62, p<.001)$. Given the double loading of item 22 , and to achieve simple structure, a further CFA was carried out removing item 22 completely from both the RS and HS subscales. When item 22 is removed completely (see model C, table 3 ), there is a slight improvement in the fit compared with when it is allowed to double-load.

\section{Figure 1 here}

While a three-factor solution has been supported here, it has been suggested (see Introduction) that a two-factor solution (combining the Inadequate-self and Hatedself factors to form a single self-criticism factor) and a one-factor solution (combining self-reassurance [reversed] and self-criticism) might also be sufficient. These alternative models were tested and revealed poor fit to the data since all fit indices were outside their recommended cut-off ranges (see models D and E respectively, table 3).

\section{Table 3 here}

FSCRS: Intercorrelations with mood and gender differences

Table 4 shows that the intercorrelations between the FSCRS subscales were similarly high in both the new 18 -item and the original 22 -item version of the FSCRS 
although there is a slight reduction in the correlation between IS and HS from the full version to the 18-item version, suggesting a slight improvement in the separation of these factors.

\section{$\underline{\text { Table } 4 \text { here }}$}

Correlations between the SDHS and the HS and RS subscales of the FSCRS were identical for both the original 22 -item and the new 18 -item versions. However, the correlation between the SDHS and the IS subscale was slightly reduced in the 18 -item version compared with the original (see table 4). Gilbert et al. (2004) reported lower correlations between the FSCRS and depression (Pearson r's ranging from -.51 to .57) although this may be due to differences in the measure of used, with Gilbert et al. (2004) using the CES-D (Radloff, 1977).

Women were significantly higher on the IS scale than men (means [s.d's] were $18.3[6.4]$ and $16.3[6.5]$ respectively, $t(1219)=-4.469, p<.001)$. Conversely, women were significantly higher on the RS scale than men (means [s.d's] were $22.2[6.8]$ and 20.6 [7.0] respectively, $t(1219)=3.372, p=.001)$, with higher scores indicating less selfreassurance. Women were higher on the HS scale than men (means [s.d's] were 9.0 [4.9] and 8.5 [4.4] respectively) although this difference was not significant, $(t(409.62)=$ $-1.649, p=.10)$. These differences are identical to those found when using the full 22 item FSCRS, with no sex differences found for the HS scale $(p=.10)$ and women scoring 
significantly higher on both the IS and RS scales than men $(p<.001$ and $p=.001$, respectively).

\section{Discussion}

A CFA was conducted to determine the factor structure of the FSCRS. To our knowledge the only study that has examined the factor structure of the FSCRS to date is the original paper in which the measure was developed (Gilbert et al., 2004).

Findings indicate that the FSCRS measures three factors; self-reassurance and two types of self-criticism referred to as inadequate-self and hated-self. This, therefore, replicates Gilbert et al.'s (2004) findings. However, the analyses revealed that several modifications were required to improve the factor structure. This included the removal of items 4, 18 and 20 due to low factor loadings. Item 22 loaded onto both the reassured-self and the hated-self components of the FSCRS. However, the fit was still quite good. Nevertheless, item 22 can be removed (should researchers prefer) without detriment to the psychometric quality of the FSCRS. The results showed that, although the factors inadequate-self and hated-self were highly correlated, a two-factor solution comprising self-reassurance and self-criticism (combining inadequate-self and hated-self into a single scale) as well as a single-factor solution (as implied by the Self-Compassion Scale; Neff, 2003a) that combined self-criticism (inversely) and self-reassurance were both poor fits to the data. The three-factor model of reassured-self, inadequate-self and hated-self proved to be the best fitting measurement model in this sample providing 
further support for Gilbert et al.'s (2004) original model, suggesting that inadequate-self and hated-self are two independent forms of self-criticism. While the three-factor model is more statistically appropriate in terms of model fit, the high inter-correlation between inadequate-self and hated-self indicates a risk for multi-collinearity issues when building predictive models of outcomes. Problems with multi-collinearity are not inevitable with high intercorrelations but researchers must nevertheless be vigilant to the possibility of these effects. However, the size of the correlation between IS and HS was lower in the modified 18 -item version than the original 22 -item version suggesting authors might usefully follow this modified scoring.

Inter-correlations between the individual subscales of the FSCRS and mood were very similar in the shorter 18 -item version and the original 22 -item version although there was a slight reduction in the size of the relationship between the two self-criticism scales from the full FSCRS to the shortened version.

Finally, sex differences were found for the IS and RS scales with women reporting more feelings of inadequacy and less self-reassurance in comparison to men. Once again, these findings suggest that self-criticism can be separated into two forms as sex differences suggest that women exhibit more negative self-evaluation in the form of feelings of inadequacy but not self-hatred when compared to men. The same sex differences were found when using both the shortened 18 -item version and the original FSCRS. Together these findings show that associations between the FSCRS with mood and sex are maintained when using a psychometrically improved version identified through confirmatory factor analysis. 
Strengths and limitations

The current study recruited a non-clinical sample and responses from a clinical group may have revealed a different factor solution. Another possible limitation is that the data were collected online and it is arguable that the use of traditional paper-andpencil methods of data collection may have led to a different set of results. However, previous research has demonstrated that online responses are generally as valid and reliable as those collected offline (Hiskey \& Troop, 2002). The current study focused on the forms of self-criticism and self-reassurance but did not measure the functions which self-criticism serves, such as self-correction and self-persecution (Gilbert et al., 2004). To gain a better understanding of self-criticism and self-reassurance, future research should also examine the factor structure of these functions, which relate to the use of self-criticism for self-improvement versus for self-punishment. Lastly, a high percentage of the sample were classed as "white" so the results of this study may not be generalisable to other ethnic groups.

The present study also has several noteworthy strengths, for example, the recruitment of a large predominantly community-based sample, which not only provided the analyses with good power but also allows for the findings to be generalised to groups outside of the student population on which the FSCRS was developed. The current study also extended the original development of the FSCRS by exploring sex differences. 
Implications

In spite of the above limitations, our findings have a number of important implications. From a theoretical point of view, the present study supported the original findings of Gilbert et al. (2004), indicating that a three-factor model consisting of reassured-self, inadequate-self and hated-self was the best fit. The use of the threefactor model will allow future research to build on our current understanding of selfcriticism in order to determine whether inadequate-self and hated-self impact differently on outcomes and/or respond differently to intervention. They are clearly separable aspects of self-criticism but the degree to which this distinction is clinically and/or theoretically meaningful requires further research. Other extant measures of self-criticism are not able to achieve this.

The confirmation of the three factors of the FSCRS also has implications for research on the aetiology of psychopathology in terms of vulnerability, responses to triggering events and risk of relapse. The demonstration of reliability and validity for the FSCRS supports its use by both clinicians and researchers to evaluate these issues and to track changes over the course of illness and treatment.

Women are significantly more likely than men to experience depression (NolenHoeksema, 2001). The sex differences found in relation to feelings of inadequacy and self-reassurance may account, in part, for this. As such it may be understood in the context of other types of response to stress or failure that have been proposed to account for sex differences in rates of depression. For example, women are more likely to ruminate than distract themselves following stress (Butler \& Nolen-Hoeksema, 1994; 
Nolen-Hoeksema, 1990) and to engage in emotion-focused coping (Matud, 2004;

Tamres, Janicki \& Helgeson, 2002).

Finally, the current paper has built on the original development of the FSCRS by expanding its generalisability from a student population to a predominantly communitybased sample. However, in order to develop the FSCRS further, emphasis must be placed on using this potentially valuable tool in other settings in order to demonstrate its generalisability to a range of diverse clinical and non-clinical groups and provide further support for its three-factor structure. 


\section{References}

Blatt, S. J., \& Homann, E. (1992). Parent-child interaction in the etiology of dependent and self-critical depression. Clinical Psychology Review, 12, 47-91.

Blatt, S. J., Quinlan, D. M., Chevron, E. S., McDonald, C. \& Zuroff, D. (1982). Dependency and self-criticism: Psychological dimensions of depression. Journal of Consulting and Clinical Psychology, 50, 113-124

Brinthaupt, T.M., Hein, M.B. \& Kramer, T.E. (2009). The Self-Talk Scale: Development, factor analysis and validation. Journal of Personality Assessment, 91, 82-92.

Butler, L. D. \& Nolen-Hoeksema, S. (1994). Gender differences in responses to depressed mood in a college sample. Sex Roles, 30, 331-346

Byrne, B. M. (1998). Structural equation modeling with Lisrel, Prelis, and Simplis: Basic concepts, applications, and programming. Mahwah, NJ: Lawrence Erlbaum Associates, Inc.

Campos, R.C., Besser, A., \& Blatt, S.J. (2010). The mediating role of self-criticism and dependency in the association between perceptions of maternal caring and depressive symptoms. Depression and Anxiety, 27, 1149-1157. 
Cantazaro, A. \& Wei, M. (2010). Adult attachment, dependence, self-criticism, and depressive symptoms: A test of a mediational model. Journal of Personality, 78, 11351162.

Coyne, J.C., Aldwin, C., \& Lazarus, R.S. (1981). Depression and coping in stressful life episodes. Journal of Abnormal Psychology, 90, 439-447.

Dunkley, D.M., Sanislow, C.A., Grilo, C.M. \& McGlashan, T.H. (2009). Self-criticism versus neuroticism in predicting depression and psychosocial impairment for 4 years in a clinical sample. Comprehensive Psychiatry, 50, 335-346.

Folkman, S. \& Lazarus, R.S. (1985). If it changes it must be a process: Study of emotion and coping during three stages of a college examination. Journal of Personality and Social Psychology, 48, 150-170.

Gilbert, P. (2005). Compassion and cruelty: A biopsychosocial approach. In P. Gilbert (Ed). Compassion: Conceptualisations, research and use in psychotherapy (pp. 3-74). London: Routledge.

Gilbert, P. (2006). Evolution and depression: Issues and implications. Psychological Medicine, 36, 287-297. 
Gilbert, $\mathrm{P}$ (2009). The compassionate mind: A new approach to the challenge of life. London: Constable \& Robinson.

Gilbert, P. (2010). Compassion focused therapy: The CBT distinctive features series. London: Routledge.

Gilbert, P. Baldwin, M.W., Irons, C., Baccus, J.R. \& Palmer, M. (2006). Self-criticism and self-warmth: An imagery study exploring their relation to depression. Journal of Cognitive Psychotherapy, 20, 183-200.

Gilbert, P., Clarke, M., Hempel, S., Miles, J.N.V., \& Irons, C. (2004). Criticizing and reassuring oneself: An exploration of forms, styles and reasons in female students. British Journal of Clinical Psychology, 43, 31-50.

Gilbert, P. \& Irons, C. (2005). Mind training for shame and self-attacking. In P. Gilbert (Ed). Compassion: Conceptualisations, research and use in psychotherapy (pp. 263-325). London: Routledge.

Gilbert, P., McEwan, K., Irons, C., Bhundia, R., Christie, R., Broomhead, C., \& Rockliff, H. (2010). Self-harm in a mixed clinical population: The roles of self-criticism, shame, and social rank. British Journal of Clinical Psychology, 49, 563-576. 
Gilbert, P., McEwan, K., Mitra, R., Franks, L., Richter, A. \& Rockliff, H. (2008). Feeling safe and content: A specific affect regulation system? Relationship to depression, anxiety, stress, and self-criticism. The Journal of Positive Psychology, 3, 182-191.

Gilbert, P., \& Procter, S. (2006). Compassionate mind training for people with high shame and self-criticism: Overview and pilot study of a group therapy approach. Clinical Psychology \& Psychotherapy, 13, 353-379.

Hiskey, S. \& Troop, N. A. (2002). Online Longitudinal Survey Research: Viability and Participation. Social Science Computer Review, 20, 250-259.

Howell, D. C. (2002). Statistical Method for Psychology (5 ${ }^{\text {th }}$ ed.). Pacific Grove, CA: Duxbury.

Irons, C., Gilbert, P., Baldwin, M.W., Baccus, J. R., \& Palmer, M. (2006). Parental recall, attachment relating and self-attacking/self-reassurance: Their relationship with depression. British Journal of Clinical Psychology, 45, 297-308.

Janoff-Bulman, R. (1992). Shattered assumptions: Towards a new psychology of trauma. New York: Free Press. 
Joseph, S., Linley, S. J., Harwood, J., Lewis, C. A., \& McCollam, P. (2004). Rapid assessment well-being: The Short Depression-Happiness Scale (SDHS). Psychology and Psychotherapy: Theory, Research and Practice, 77, 463-478

Kupeli, N., Chilcot, J., Platts, E. \& Troop, N.A. (2011). Stress, mood and eating pathology: The role of self-criticism, self-reassurance and self-esteem. Submitted.

Leadbeater, B. J., Kuperminc, G. P., Blatt, S. J. \& Hertzog, C. (1999). A multivariate model of gender differences in adolescents' internalizing and externalizing problems. Developmental Psychology, 35, 1268-1282

Longe, O., Maratos, F.A., Gilbert, P., Evans, G., Volker, F., Rockliff, H. \& Rippon, G. (2010). Having a word with yourself: Neural correlates of self-criticism and selfreassurance. Neuroimage, 49, 1849-1856.

Matud, M. P. (2004). Gender differences in stress and coping styles. Personality and Individual Differences, 37, 1401-1415

Mayhew, S. L., \& Gilbert, P. (2008). Compassionate mind training with people who hear malevolent voices: A case series report. Clinical Psychology \& Psychotherapy, 15, $113-$ 138. 
Muthén, L. K. \& Muthén, B. O. (2010). Mplus Version 6. Los Angeles, CA: Muthén \& Muthén

Neely, M.E., Schallert, D.L., Mohammed, S.S., Roberts, R.M. \& Chen, Y.-J. (2009). Selfkindness when facing stress: The role of self-compassion, goal regulation, and support in college students' well-being. Motivation and Emotion, 33, 88-97.

Neff, K. D. (2003b). Self-compassion: An alternative conceptualization of a healthy attitude toward oneself. Self and Identity, 2, 85-101.

Neff, K. D. (2003a). The development and validation of a scale to measure selfcompassion. Self and Identity, 2, 223-250.

Neff, K.D. (2004). Self-compassion and psychological well-being. Constructivism in the Human Sciences, 9, 27-37.

Neff, K.D. (2009). The role of self-compassion in development: A healthier way to relate to oneself. Human Development, 52, 211-214.

Neff, K.D. (2011). Self-compassion: Stop beating yourself up and leave insecurity behind. New York, U.S.: Harper Collins. 
Neff, K.D., Kirkpatrick, K.L., \& Rude, S.S. (2007a). Self-compassion and adaptive psychological functioning. Journal of Research in Personality, 41, 139-154.

Neff, K.D. \& McGehee, P. (2010). Self-compassion and psychological resilience among adolescents and young adults. Self and Identity, 9, 225-240.

Neff, K.D., Rude, S.S. \& Kirkpatrick, K.L. (2007b). An examination of self-compassion in relation to positive psychological functioning and personality traits. Journal of Research in Personality, 41, 908-916.

Neff, K.D., \& Vonk, R. (2009). Self-compassion versus global self-esteem: Two different ways of relating to oneself. Journal of Personality, 77, 23-50.

Nolen-Hoeksema, S. (1990). Sex differences in depression. Stanford, CA: Stanford University Press

Nolen-Hoeksema, S. (2001). Gender differences in depression. Current Directions in Psychological Science, 10(5), 173-176

Nolen-Hoeksema, S., Larson, J. \& Grayson, C. (1999). Explaining the gender difference in depressive symptoms. Journal of Personality and Social Psychology, 77, 1061-1072 
Powers, T.A., Koestner, R., Lacaille, N., Kwan, L. \& Zuroff, D.C. (2009). Self-criticism, motivation and goal progress of athletes and musicians: A prospective study. Personality and Individual Differences, 47, 279-283.

Radloff, L. S. (1977). The CES-D scale: A new self-report depression scale for research in the general population. Applied Psychological Measurement, 1, 385-401

Reynolds, M., \& Wells, A. (1999). The Thought Control Questionnaire: Psychometric properties in a clinical sample and relationships with PTSD and depression. Psychological Medicine, 29, 5, 1089-1099.

Richter, A., Gilbert, P. \& McEwan, K. (2009). Development of an Early Memories of Warmth and Safeness scale and its relation to psychopathology. Psychology and Psychotherapy: Theory, Research and Practice, 82, 171-184.

Rockliff, H., Karl, A., McEwan, K., Gilbert, J., Matos, M., \& Gilbert, P. (2011). Effects of intranasal oxytocin on "compassion focused imagery". Emotion. In press.

Tamres, L. K., Janicki, D. \& Helgeson, V. S. (2002). Sex differences in coping behaviour: A meta-analytic review and an examination of relative coping. Personality and Social Psychology Review, 6, 2-30 
Tobin, D.L., Holroyd, K.A., Reynolds, R. \& Wigal, J.K. (1989). The hierarchical factor structure of the Coping Strategies Inventory. Cognitive Therapy and Research, 13, 343361.

Troop, N.A., Choudhury, M., Wiseman, J., Hore, B. \& Ratcliff, L. (2012). Affect systems and disordered eating: Attachment, social rank and self-criticism. Submitted.

Vitaliano, P.P., Russo, J., Carr, J.E., Maiuro, R.D., \& Becker, J. (1985). The Ways of Coping Checklist: Revision and psychometric properties. Multivariate Behavioural Research, 20, 3-26. 
Table 1: Demographic variables across EFA and CFA split sample

\begin{tabular}{|c|c|c|c|c|}
\hline $\begin{array}{l}\text { Demographic } \\
\text { Variables }\end{array}$ & $\begin{array}{l}\text { Total } \\
(n=1570)\end{array}$ & $\begin{array}{l}\text { EFA Sample } \\
(n=764)\end{array}$ & $\begin{array}{l}\text { CFA Sample } \\
(n=806)\end{array}$ & Significance \\
\hline Age (SD) & $28.5(10.6)$ & $28.6(10.6)$ & $28.3(10.6)$ & $t(1568)=.54 p=.59$ \\
\hline Male $\%(n)$ & $17.5(275)$ & $18.1(138)$ & $17.0(137)$ & Fisher's Exact test $p=.60$ \\
\hline Female $\%(n)$ & $82.5(1295)$ & $81.9(626)$ & $83.0(669)$ & \\
\hline Ethnicity-white \% (n) & $75.3(1182)$ & $49.2(582)$ & $50.8(600)$ & Fisher's Exact test $p=.45$ \\
\hline \multicolumn{5}{|l|}{ Marital Status \% (n) } \\
\hline Single & $39.6(621)$ & $37.7(288)$ & $41.3(333)$ & \\
\hline Married & $20.8(326)$ & $22.5(172)$ & $19.1(154)$ & \\
\hline Divorced & $3.3(52)$ & $3.0(23)$ & $3.6(29)$ & $\chi^{2}(\mathrm{df}=5)=6.44 p=.27$ \\
\hline Living with partner & $18.2(286)$ & $19.6(150)$ & $16.9(136)$ & \\
\hline In a relationship & $17.8(280)$ & $16.9(129)$ & $18.7(151)$ & \\
\hline Widowed & $.3(5)$ & $.3(2)$ & $.4(3)$ & \\
\hline \multicolumn{5}{|l|}{ Employment \% (n) } \\
\hline Employed & $42.7(671)$ & $42.8(327)$ & $42.7(344)$ & \\
\hline Unemployed & $9.2(144)$ & $10.2(78)$ & $8.2(66)$ & $\chi^{2}(\mathrm{df}=2)=2.12 p=.35$ \\
\hline Student & $48.1(755)$ & 47.0 (359) & $49.1(396)$ & \\
\hline
\end{tabular}


Table 2: EFA solution for the FSCRS

\begin{tabular}{|c|c|c|c|c|}
\hline \multirow[b]{2}{*}{ No. } & \multirow[b]{2}{*}{ Item } & \multicolumn{3}{|c|}{ Factor } \\
\hline & & 1 & 2 & 3 \\
\hline 1 & I am easily disappointed with myself. & .83 & -.004 & .01 \\
\hline 2 & There is a part of me that puts me down. & .88 & .05 & -.01 \\
\hline 6 & There is a part of me that feels I am not good enough. & .64 & .24 & .02 \\
\hline 7 & I feel beaten down by my own self-critical thoughts. & .58 & .31 & .01 \\
\hline 14 & I remember and dwell on my failings. & .55 & .19 & .01 \\
\hline 17 & I can't accept failures and setbacks without feeling inadequate. & .47 & .23 & -.08 \\
\hline 9 & I have become so angry with myself that I want to hurt or injure myself. & -.11 & .73 & .01 \\
\hline 10 & I have a sense of disgust with myself. & .07 & .81 & -.004 \\
\hline 12 & I stop caring about myself. & -.03 & .70 & .13 \\
\hline 15 & I call myself names. & .24 & .56 & -.09 \\
\hline 22 & I do not like being me. & .04 & .67 & .21 \\
\hline 3 & I am able to remind myself of positive things about myself. & .11 & .01 & .61 \\
\hline 5 & I find it easy to forgive myself. & .25 & -.03 & .46 \\
\hline 8 & I still like being me. & .03 & .34 & .57 \\
\hline 11 & I can still feel lovable and acceptable. & -.02 & .27 & .65 \\
\hline 13 & I find it easy to like myself. & .11 & .15 & .67 \\
\hline 16 & I am gentle and supportive with myself. & .35 & -.01 & .55 \\
\hline 19 & I am able to care and look after myself. & -.04 & .23 & .41 \\
\hline 21 & I encourage myself for the future. & -.02 & .19 & .57 \\
\hline \multicolumn{2}{|c|}{ Eigen value } & 9.03 & 1.67 & 1.28 \\
\hline
\end{tabular}


Table 3: Summary of CFA results for the several FSCRS models and fit indices

\begin{tabular}{llccccccc}
\hline Model & & Chi-Square & No of free & df & P-value & CFI & TLI & RMSEA \\
& & & Parameters & & & & & \\
\hline A & FSCRS from EFA & 959.1 & 98 & 149 & $<.001$ & .958 & .952 & .080 \\
B & Modified FSCRS from EFA & 800.3 & 99 & 148 & $<.001$ & .966 & .961 & .074 \\
C & Item 22 removed & 712.4 & 93 & 132 & $<.001$ & .967 & .962 & .074 \\
D & Two-factor FSCRS & 1445.4 & 96 & 151 & $<.001$ & .933 & .924 & .103 \\
E & One-factor FSCRS & 3064.0 & 110 & 209 & $<.001$ & .867 & .853 & .130 \\
\hline
\end{tabular}


Table 4: Intercorrelations between the FSCRS subscales and SDHS $(N=1221)$

\section{8-item FSCRS}

$\begin{array}{lll}\text { SDHS } & \text { RS }\end{array}$

RS $-.66^{* * *}$

HS $-.66^{* * *} \quad .61^{* * *}$

IS $\quad-.60^{* * *} \quad .60^{* * *} \quad .69 * * *$

\section{2-item FSCRS}

$\begin{array}{lll}\text { SDHS } & \text { RS }\end{array}$

RS $-.66^{* * *}$

HS $-.66^{* * *} \quad .61^{* * *}$

IS $\quad \begin{array}{lll}-.62^{* * *} & .60^{* * *} & .73^{* * *}\end{array}$

Note. ${ }^{* * *} p<.001$ 
Figure 1: CFA: Modified FSCRS model.

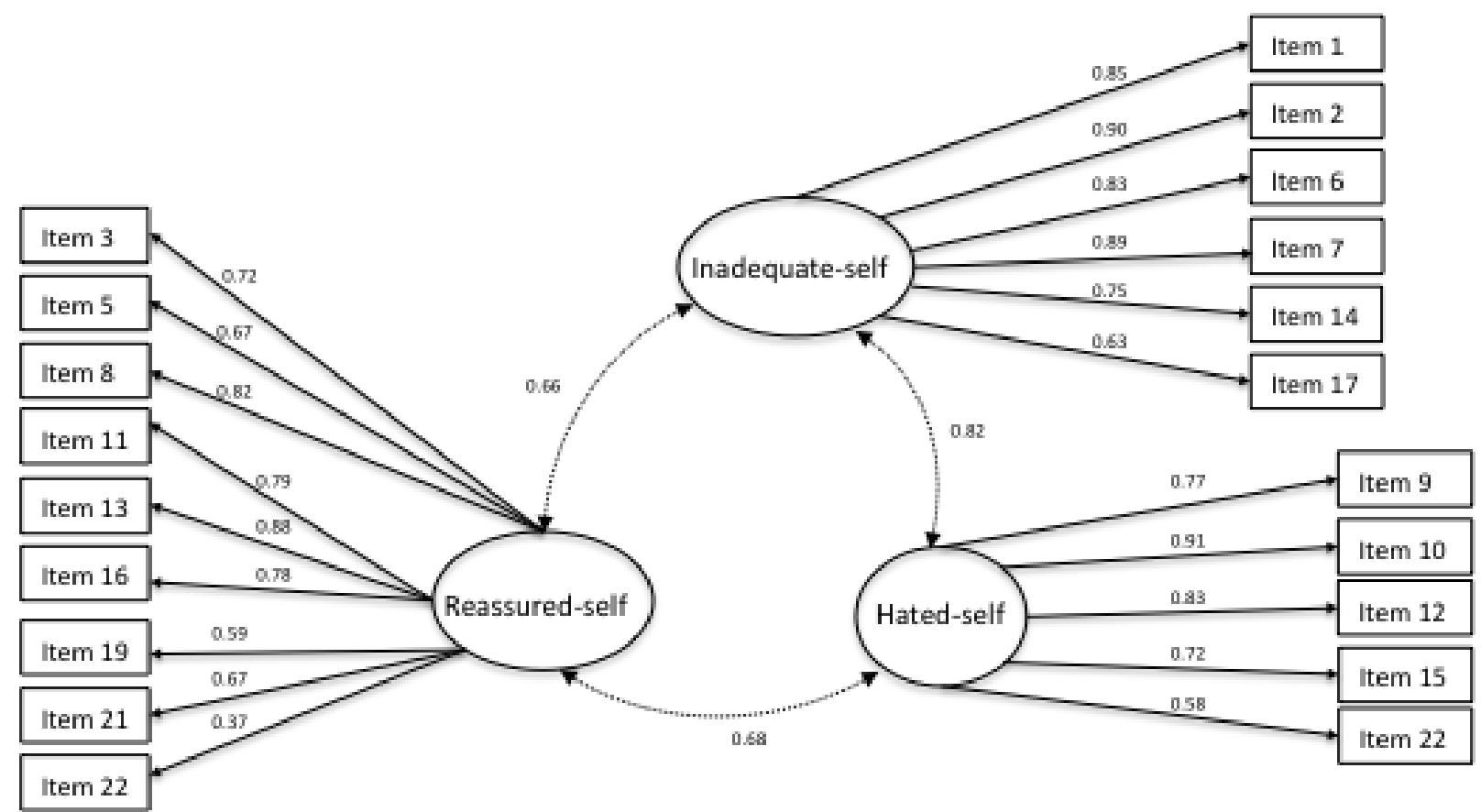

